\title{
Study of Trabekular Anatomic Structures on Biawak Water Bone (Varanus Salvator)
}

\author{
Haniaturizqia*, Amalia Hasni, Miftahul Anwar \\ Biology Education Department, Faculty of Science and Technology, UIN Sunan Kalijaga \\ Jl. Marsda Adisucipto No 1 Yogyakarta 55281, Indonesia. Tel. +62-274-540971, Fax. +62-274-519739. \\ Email*: haniarizqi@gmail.com
}

\begin{abstract}
Asian water lizards (Varanus salvator) is one of the species that is widespread in the region of South Asia and Southeast Asia, one of which is in the territory of Indonesia. One of the characteristics of water lizards is having a tail that serves to maintain the balance of his body when moving. This study aims to determine the anatomical structure of the trabeculae in the tailbone of the Asian water lizard (Varanus salvator). Trabeculae are derived from the aquatic biawaks tailbone, which is neutralized with chloroform and then dissected. The coccyx is taken and prepared for observation of trabecular anatomy by sanding part of the coccyx. Then observed the structural parts of the trabeculae using a microscope. Bone trabeculae can be seen as small, porous and porous tissue elements, which consist of trabekulated tissue. Based on the results of the study it can be concluded that the trabeculae of the monitor lizard's tail bone consist of thin lattice elements and form spongy bones. The trabecular structure is thicker and denser to withstand external loading that is optimally regulated to withstand loads in functional activities such as jumping, running and for body balance. So that the dense trabecular structure of the monitor lizard's tailbone can function optimally for the balance of the body of Asian water lizards in moving and doing activities.
\end{abstract}

Keywords: Trabeculae, Coccyx, Water Lizard (Varanus salvator)

\section{INTRODUCTION}

Indonesia has a type of giant lizard that is rare and highly protected, and has not received much attention from researchers, namely monitor lizards. Lizards can be divided into several types which are spread on various islands in Indonesia. One type of monitor lizard that is often found is water lizard (Varanus salvator) (Koch et al. 2013). According to Koch and Acciaioli (2007), water lizards spread from Sumatra, Java to Sulawesi and Maluku. Varanus indicus in Papua and Australia, while other types are Varanus komodoensis (Komodo dragons) which have spread on Komodo Island, East Nusa Tenggara and Varanus auffenbergi scattered on Roti Island. Lizards have been hunted for hundreds of thousands of years by humans to use their skin as materials for the handicraft industry and their meat as food or medicine (Shine et al. 1996). Water lizards included in the Genus Varanus have long necks, tails, strong claws, and well-developed limbs. Lizards are a type of large reptile that can run up to 20 kilometers per hour and can swim well. To catch prey that is out of range, this type of large reptile can stand on its back with its hind legs and use its tail as a support and balance in movement (Burnie and Wilson 2001).

The behavior of water lizards that are able to withstand external loads and maintain balance in activity is thought to have a close relationship with the structure of the tailbone so that this body part is interesting to study. So far there have not been many studies on the structure of the aquatic lizard's tailbone which is associated with the body's balance function. Therefore, the study of the structure of the coccyx needs to be done. One of the Lizard tail bone structures is composed of trabeculae which can be observed using a microscope and look like a small, septated and porous tissue element, which consists of trabekulated tissue, which forms a denser arrangement to resist external loads.

\section{MATERIALS AND METHODS}

The samples used in this study were adult water lizard tail organ, water lizard mutilated with chloroform and performed surgery on the tail then cleaned the tail bone using sandpaper to the middle of the bone. Next, the trabecular arrangement of the monitor bones of the monitor lizard was observed using a stereo microscope. Then the results obtained are photographed. Data from observations of water lizard trabecular structure were analyzed descriptively.

\section{RESULT AND DISCUSSION}

\section{Water Lizard (Varanus Salvator)}

The population of water lizards found on the island of Java is very high. Sandy sandy contours on the island make it an ideal place for water lizards to build nests and store their eggs (De Lisle 2007). The monitor lizard's habitat is in a river or lake. These animals have an aggressive nature, often attacking humans or other 
animals by wagging their tails and clawing with sharp nails (Traeholt 1993).

According to Koch et al. (2013), the classification of water lizards is as follows:

$\begin{array}{ll}\text { Class } & \text { : Sauropsida } \\ \text { Order } & \text { : Squamata } \\ \text { Family } & \text { : Varanidae } \\ \text { Genus } & \text { : Varanus } \\ \text { Species } & \text { : Varanus salvator } \\ \text { Source } & \text { : Zug (1993) }\end{array}$

The Varanidae family has features such as: a large body with rounded scales on the dorsal section, a fold of skin on the neck and body, a long neck with a head covered by polygonal-shaped scales. In addition, the Varanidae family has other features, namely a long forked tongue with pleurodont tooth type, rounded pupils with obvious eyelids and ear holes. Species of the Varanidae family include water lizards (Varanus salvator) and Komodo dragons (Varanus komodoensis) whose length is more than 3 meters (Zug 1993).

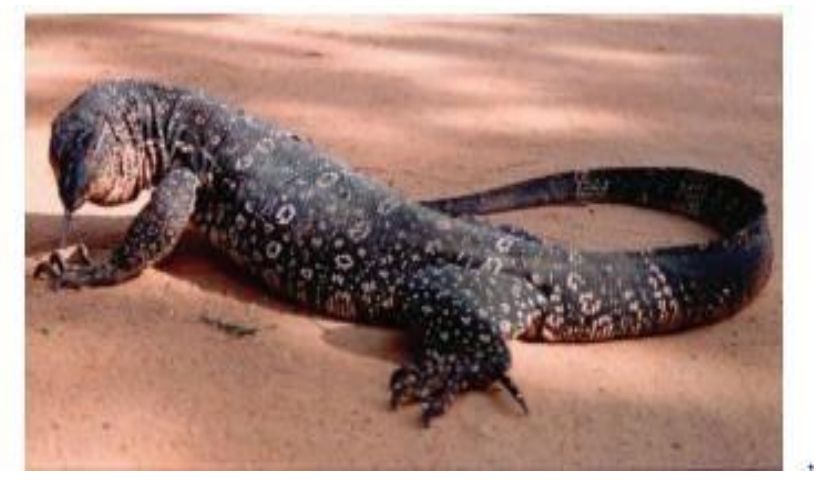

Figure 1. Lizard in Lahugala National Park Sri Lanka. (Wickramasinghe et al. 2010)

The water lizard is equipped with a long and very strong tail, this tail can help it swim and paralyze its prey or enemy with a flickering tail (Figure 2) (Wickramasinghe et al. 2010). Burnie and Wilson (2001) state that monitor lizards can catch prey that is out of reach by standing on their hind legs and using their tails as a support.

The aquatic lizard is a large Varanus species, which can reach 2.5 meters in length from head to tail. This animal has scaly skin, thick black on the dorsal, equipped with a round or yellow stripe pattern. While the ventral skin has thick yellow scales (Figure 1). Dark water monitor lizards function absorbs the sun's heat to regulate physiological functions of body temperature (Bartholomew, 1982).

\section{Anatomical Structure of Lizard Tail Trabeculae}

Trabeculae are small, microscopic tissue elements that are sponges and thin lattices as a support or stem that supports the skeleton of internal parts of the body or organ. Trabeculae generally have mechanical functions, and usually consist of solid collagen tissue. They can consist of other ingredients such as muscles and bones (Goo Soyeon, 2009). Trabecular bone, also called cancellous bone, is a porous bone consisting of trabeculated bone tissue. These can be found at the ends of long bones such as the femur and coccyx where the bones are actually not solid but are full of holes connected by thin rods and bone tissue plates.

Although trabecular bones contain many holes, the complexity of the space provides maximum strength with minimum mass. The trabecular bone structure is arranged to optimally withstand the burden of functional activities, such as jumping, running and crouching. And according to the famous Wolff's Law, proposed in 1892 , the external shape and internal architecture of the bone is determined by the external pressure acting on it. The internal structure of the trabecular bone first undergoes adaptive changes along the stress direction and then the external cortical bone undergoes secondary changes. Eventually the bone structure becomes thicker and denser to resist external loading (Hayes, Wilson C, 1993).

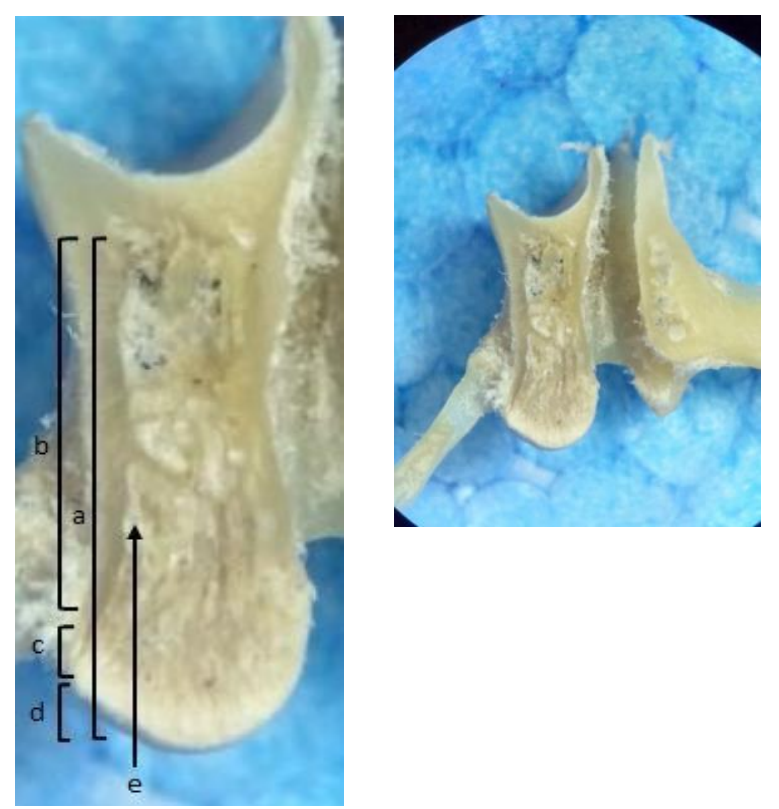

Figure 2. a. Trabekula, b. Epiphyses, c. Metaphysical, d. Diafisis, e. Trabecular sponge

Different epiphyseal and diaphysis structures are separated by broad radio-transparent bands that correspond to growth cartilage that is not calibrated in the metaphysical area which can clearly be detected. The metaphysical trabecula is not extended to the epiphyses, and there is a seam between the epiphyses and the metaphysis. All bones have an outer layer called the cortex that is smooth, dense, continuous, and with varying thicknesses. Inside, bone tissue is arranged in a network of intersecting plates and spicules called trabeculae, the amount of which varies in different bones and closed spaces filled with blood vessels and marrow. This honeycomb bone is called cancellous or trabecular. 
In mature bones, the trabeculae are arranged in a regular pattern which gives a continuous unit of bone tissue that is parallel to the lines of pressure or major tensile forces. The trabeculae thus provides a series of intricately arranged cross-bracing interior struts in such a way that it provides maximum rigidity with minimal material.

Long bones, typical of body extremities, show a number of common rough structural features. The middle region of the bone (diaphysis) is the clearest tubular. At one or both ends, the diaphysis extends out and assumes an internal structure which is largely cancellous. This region (metaphysical) functions to move the load from the connection surface that holds the load to the diaphysis. Finally, at the end of the long bone is an area known as epiphyseal, which shows an internal structure that is invalidated and consists of substructure bones of the joint surface. Before full skeletal maturity, epiphyses are separated from metaphysis by the cartilaginous plates called growth or physical plates; in bones with complex articulations (such as the humerus at the lower end) or bones with double protrusions (such as the femur on the upper end) there may be several separate epiphyses, each with a growth plate. (Donald and Roberth, 2011).

\section{CONCLUSION}

Trabecular anatomical structure in monitor lizards is arranged in a compact and sturdy. In Trabecular also called cancellous bone. Trabecular water lizard tails have diaphysis, metaphysis, epiphisis, and sponges. Diaphysis is in the middle trabecular region. At one or both ends, the diaphysis extends out and assumes an internal structure which is largely cancellous. Metaphysical function is to move the load from the connection surface that holds the load to the diaphysis. at the end of the long bone there is an area known as the epiphyseal, which shows the internal structure of the trabecular and consists of the bone substructure of the joint surface. So the coccyx can provide a function to support external loads.

\section{REFERENCES}

Bartholomew GA. 1982. Physiological control of body temperature. J Reptilia Biol. 12: 167- 211.

Burnie D, Wilson DE. 2001. Animal. New York (US): DK Publishing, Inc.

De Lisle HF. 2007. Observations on Varanus salvator in North Sulawesi. Journal of Varanid Biology and Husbandry 1 (2): 59-66.

Koch AM, Acciaioli G. 2007. The monitor twins: a bugis and Makassarese tradition from Sulawesi, Indonesia. Monitor lizard. Quarterly Journal of Varanid Biology and Husbandry 1 (2): 77-82.

Koch AM, Ziegler T, Böhme W, Arida E, Auliya M. 2013. Pressing problems: distribution, threats, and conservation status of the monitor lizards (Varanidae: Varanus spp.) Of Southeast Asia and the Indo-Australian Archipelago. Journal of the Herpetological Conservatiaon and Biology 8 (monograph 3).

Shine R, Harlow PS, Koegh JS. 1996. The biology of water monitors Varanus salvator in Southern Sumatra. Journal of Biological Conservation.

Soyeon, Goo Joshi, Purva; Sands, Greg; Gerneke, Dane; Taberner, Andrew; Dollie, Qaasim; LeGrice, Ian; Loiselle, Denis 2009. "Trabeculae carneae as a ventricular wall model: implications for oxygen delivery" (PDF). Journal of General Physiology 134 (4): $339 \quad 350 . \quad$ doi: 10.108 / jgp.200910276.ISSN00221295. PMC 2757768. PMID19752188

Traeholt C. 1993. Notes of the feeding behavior of the water monitor (Varanus salvator). Malay Nat J. 46: 229-241.

Wickramasinghe LJM, Kekulandala LDCB, Peabotuwage PIK, Karunarathna DMSS. 2010. A Remarkable feeding behavior and a new distribution record of Varanus salvator (Laurenti $1768)$ in eastern Sri Lanka. Journal of Varanid Biology and Husbandry 4 (3): 93-96.

Wedhon, G. Donald and Robert. Bone anatomy. Article www. https://britannica.com/science/bone-anatomy accessed on: $11 / 22 / 2019$

Wilson, Hayes, C, (Keaveny, Tony M. 1993). Bone: A Treatise (7th ed.). CRC Press. p. 285- 344. ISBN 978-0849388279.

Zug GR. 1993. Herpetology: An Introductory Biology of Amphibians and Reptiles. Sandiego (USA): Academic Pr. 
THIS PAGE INTENTIONALLY LEFT BLANK 